\title{
PROYECTOS VITALES DE MUJERES GITANAS UNIVERSITARIAS: ABRIENDO CAMINOS, ACOGIENDO TRADICIONES
}

\author{
Patricia Vargas del Amo \\ Universidad de Málaga
}

\begin{abstract}
RESUMEN: En este artículo se presenta una síntesis de los primeros resultados de una investigación más amplia, dirigida a la búsqueda de información a partir de las historias de vida de cuatro mujeres gitanas. Su propósito es indagar en los factores que han intervenido en el éxito y vidas académicas prolongadas de estas mujeres, hasta concluir estudios universitarios o estar actualmente cursándolos. Se ha prestado atención al significado de sus experiencias en la construcción de sus proyectos de vida y el sentido que le dan al éxito educativo. Como camino para la búsqueda de información he utilizado una metodología narrativa, optando por las historias de vida, a partir de un contexto conversacional donde las entrevistas se han entendido como un espacio para la escucha activa. A partir de estas historias de vida se gesta este documento, tomando fragmentos de las mismas para abordar las dimensiones de análisis, ahondando en la importancia del apoyo y acompañamiento a lo largo de sus trayectorias por parte de la familia y de docentes, para acercarnos y acoger la experiencias educativas de éxito y continuidad de estas cuatro mujeres universitarias, distintas entre ellas pero con un punto de partida común: el ser mujeres, ser gitanas y dotar de significado e importancia a la vida académica.
\end{abstract}

PALABRAS CLAVES: Mujer gitana, éxito educativo, proyecto de vida, docentes, familia.

\section{VITAL PROJECTS OF UNIVERSITY GYPSY WOMEN: OPENING ROUTES, WELCOMING TRADITIONS}

\begin{abstract}
The article aims to show a synthesis of the first results obtained from a broader research, focused on finding information from the life histories of four gypsy women, regarding the factors that have intervened in the successful and prolonged academic lives, so far to conclude university studies or being currently attending, together with the construction of their life projects, based on the meaning of their experiences and the sense they give to
\end{abstract}


the concept of educational success. As a way to search for information I have used a narrative methodology, opting for life histories, giving space to listening from a conversational context where the interviews have been understood as a communicative exchange. It is from these life stories that this document is born, taking from them some fragments to analyze dimensions, delving into the importance of the support and accompaniment of their families and teachers along their career paths, to approach the educational experiences of success and continuity of these four university women, different from each other but with a common starting point, being women, being gypsies and endowing meaning and importance to academic life.

KEYWORDS: Gypsy woman, Academic success, life proyect, teachers, family.

Recibido: 30/03/2017

Aceptado: 30/09/2017

Correspondencia: Patricia Vargas del Amo, Facultad Ciencias de la Educación, Bulevar Louis Pasteur, 25, Campus de Teatinos, 29010 Málaga. Email: pvda82@hotmail.com.

\section{INTRODUCCIÓN}

Nos encontramos en un momento histórico en el que se está produciendo un cambio cultural que afecta al contexto social en el que vivimos. Respecto a la población gitana, este contexto social está afectando a la construcción de su identidad, a las reglas de parentesco, a la autoridad y a sus creencias, de tal modo que "algunos símbolos desaparecen, otros pierden relevancia, ciertas normas se relativizan y hay valores que se ponen en cuestión" (Andrés, s.f.). Acompañando a dicho cambio social, la mujer ha ido progresivamente asumiendo diferentes parcelas de la realidad, incrementando la visibilidad de su presencia en todos los órdenes de la vida humana.

Si esto ha sucedido con las mujeres en general, tomando la pregunta de Da Fosenca (2009), ¿qué puede decirse de la invisibilidad de las mujeres gitanas que no han tenido voz social hasta hace menos de veinte años?

Esta es la cuestión que marca el inicio de esta investigación: mostrar la nueva imagen de la mujer gitana, a partir del análisis de las historias de vida de cuatro de ellas, que han decidido tener una vida académica prolongada y con éxito educativo, construyendo sus proyectos vitales a partir de factores transformadores propios. Al hacerlo han roto con la imagen estereotipada de "mujer gitana", considerándose como agentes activos en la toma de decisiones y desarrollo de sus vidas con capacidad de transformación en la sociedad y dentro de su comunidad, a pesar de las diferencias familiares, sociales, culturales y experienciales.

Las mujeres gitanas se han encontrado a lo largo de la historia entre la espada y la pared, padeciendo una situación diferente como grupo étnico-cultural con respecto a la mayoría, viéndose afectadas por ser mujeres en una sociedad patriarcal, por pertenecer a una minoría étnica valorada socialmente a partir de prejuicios, y 
por vincularse a una cultura cuyos valores de género están asociados a su función como madres y esposas (Márquez y Padua, 2009; Montañés Álvarez, 2011; Valls y Aubert, 2003). A esto se une, como apunta Puigvert (2001), carecer en muchos casos de formación académica para acceder a niveles de participación en igualdad de condiciones.

Ante esta situación, las mujeres gitanas se encuentran en la encrucijada de responder tanto al rol que el grupo de pertenencia espera que desempeñen, como a conseguir el estatus que desean dentro de una sociedad que les ofrece otras posibilidades.

Es por ello que en la actualidad, como afirman diferentes autores (Márquez y Padua, 2009; Villalba, 2000; Montañés Álvarez, 2011), coexisten diversas realidades respecto al rol de la mujer gitana, donde conviven valores más tradicionales con valores nuevos emergentes de la participación de las mujeres gitanas en diferentes ámbitos de la sociedad, que reflejan que modernidad y tradición van unidas estrechamente.

Como señala Villalba (2000), la mujer gitana ha participado activamente en la incorporación a espacios educativos reglados y no reglados desde hace ya veinticinco años, indicando que son ellas las que han comprendido la necesidad de incorporar a las niñas y niños gitanos al sistema educativo reglado y, por lo tanto, han potenciado los cambios necesarios para que esto se produzca en situación de normalidad.

Tal y como se podrá observar a través de los extractos de las historias de vida, las mujeres gitanas buscan compatibilizar ambos espacios, enfrentándose al reto de articular tradición y progreso, configurando una nueva identidad que responda a ambas exigencias, dando lugar a nuevos modelos y referencias y contribuyendo con ello al desarrollo de la comunidad.

Cada vez son más las mujeres gitanas que toman conciencia de su situación y, como indican Valls y Aubert (2003), se organizan para cambiar su contexto y reivindicar una igualdad de derechos desde su diferencia, considerando la educación tanto instrumento como espacio para poder crear situaciones de diálogo desde los que su figura y su identidad sean reconocidas. Pero no debemos caer en el error de generalizar, ya que las realidades entre mujeres gitanas, al igual que en el resto de la población son muy diversas, viéndose condicionadas por su la situación laboral, de vivienda, el ámbito geográfico y sus posibilidades educativas.

En este marco, la institución educativa juega un papel importante para la vida de las niñas gitanas, como lugar de encuentro, acogida y diálogo entre culturas, desde donde se posibilite, potencie y anime la promoción académica y al éxito educativo (Abajo y Carrasco, 2004; Colectivo loé, 2015; FSG, 2006).

El éxito educativo es un concepto que suele ser ambigüo y difícil de precisar. En este caso, y de acuerdo a la consideración que realizan García y Blanco (2015), se entiende el éxito escolar como la conjunción de una actitud positiva hacia la escuela y hacia los saberes, de responsabilidad y constancia en el trabajo continuado, de buenos resultados académicos, de superación de obstáculos y de integración en el grupo clase con el profesorado y los compañeros. El éxito escolar, por tanto, se aborda desde una dimensión vital conectada al sentido que los jóvenes atribuyen a su estar en la escuela, a su relación con el saber, y a la conexión de éste con su vida (Hernández y Padilla, 2013). 
Así mismo, Gamella (2011) al hablar de éxito educativo, se refiere al grado de éxito obtenido en la titulación, las expectativas acerca de la continuación de los estudios o formación, además de la motivación por el aprendizaje continuo y la confianza en las propias capacidades para abordar los retos de la formación de manera exitosa.

En los últimos años se han producido un buen número de investigaciones y estudios que nos ofrecen datos relevantes sobre la situación escolar de la población gitana (Abajo y Carrasco, 2004; CNIIE, 2014; Colectivo loé, 2015; CREA, 2010; FSG, 2006, 2010 y 2013; Gamella, 2011; Laparra, 2011; Márquez y Padua, 2009). De ellos se desprende que el tránsito educativo de las niñas y adolescentes gitanas a través de las distintas etapas educativas no se produce de manera lineal, sino que va sufriendo diversos altibajos en cuanto a la asistencia, abandono escolar, resultados académicos y reincorporación al sistema educativo.

Desde el acceso a educación primaria comienzan las primeras diferencias entre alumnos y alumnas gitanas, siendo ellas las que se escolarizan en mayor proporción después de los seis años (FSG, 2010). Posteriormente son ellas las que muestran mejores resultados en cuanto a la adquisición de ritmos, rutinas, normas escolares, actitudes hacia el diálogo, cuidado del material y rendimiento académico, así como menor el número de ausencias prolongadas (Colectivo loé, 2015).

Es durante el tránsito entre educación primaria y educación secundaria obligatoria (ESO) cuando se truncan las trayectorias educativas de las adolescentes gitanas, siendo menor el número de chicas que acceden a la ESO, respecto a los chicos (FSG, 2006). Sin embargo, al llegar a $4^{\circ}$, los datos se invierten siendo el porcentaje de chicas gitanas casi el doble al de los chicos. Este dato es significativo puesto que indica que son las chicas las que obtienen mejores resultados en el proceso educativo, con un menor grado de desfase curricular respecto a los estudiantes gitanos, con una tasa menor de repeticiones a los 15 años (Colectivo loé, 2015), al mismo tiempo que a lo largo de la ESO expresan mayores aspiraciones de formación y de ejercer una profesión con titulación superior (FSG, 2006). Por tanto, y como indica el estudio de la FSG (2010), el porcentaje de niñas que quieren seguir estudiando más allá de los estudios obligatorios es superior al de niños.

Una vez realizado el tránsito por la ESO, los itinerarios elegidos son diferentes estando las chicas más presentes en bachillerato, lo cual está relacionado con la afirmación anterior respecto a las expectativas de las adolescentes gitanas hacia estudios superiores (Colectivo loé, 2015).

Otra diferencia importante es la relacionada con las expectativas en cuanto al matrimonio y/o la dedicación a la vida doméstica, que es señalada en mucha mayor medida por las chicas, y que explica el índice de adolescentes gitanas que abandonan la ESO.

Según la encuesta de la FSG (2013), la tasa de reincorporación por parte de las estudiantes gitanas entre los 18 y 24 años, es superior a la de los chicos, destacando en el caso de las chicas aquellas que ahora sí pueden continuar y dejando entrever la presencia invisible de las familias a la hora de crear sus itinerarios académicos y por consiguiente sus proyectos de vida. En estos casos, estas chicas (en mayor medida que los chicos), orientan su esfuerzo a la obtención del título de Secundaria y de Bachillerato. 
Por último, un $80 \%$ de la población gitana que accede a la universidad son mujeres, lo que hace ver que la mujer gitana es el motor de cambio dentro de su ámbito, y que son ellas las que están trabajando por avanzar, constituyéndose en piezas claves para el desarrollo del colectivo (Montañés Álvarez, 2011).

Es de esperar que en un futuro próximo se incremente la presencia de las mujeres gitanas en estudios superiores y universitarios. Como muestran los datos que se presentan a continuación, para favorecer esa presencia hay que considerar la importancia del acompañamiento por parte de la familia y los docentes para facilitar la prolongación de la vida de estas mujeres gitanas dentro del sistema educativo. Porque en esa decisión no sólo entran en juego sus capacidades académicas sino también los sistemas de mediación social y familiar para poder hacer frente a las dificultades encontradas a lo largo del camino, ya que a través de sus actos y palabras deben mostrar que son capaces de articular tradición y progreso en relación con su identidad cultural.

\section{Método}

Los resultados que se ofrecen forman parte de un estudio más amplio (para la tesis doctoral) que nace del propósito de conocer qué elementos han intervenido, qué condiciones se han dado y qué motivaciones han existido para favorecer el éxito educativo de cuatro mujeres gitanas que han concluido sus estudios universitarios.

En este caso, el análisis se centra en la importancia del acompañamiento familiar, junto con la acogida y relaciones con docentes, para contribuir a la permanencia de estas estudiantes dentro del sistema educativo, transitando con éxito en el mismo, así como las herramientas utilizadas como base de negociación entre su desarrollo como mujer y su herencia de mujer gitana.

Se ha optado por un método biográfico narrativo a partir de historias de vida, considerando la importancia de la elección metodológica (Pujal, 2003), y de "pensar el método como camino es una renuncia a prescribir la investigación, lo que no significa renunciar a mantener una relación firme orientada en el estudio" (Sierra, 2003, p. 79).

Conocer los proyectos de vida de estas mujeres lleva al interés sobre la experiencia humana como eje de análisis, como la entiende Bolivar (2002) dirigida al entendimiento y al hacer sentido de dicha experiencia. De ahí la elección del método, ya que "la narrativa se sitúa en la experiencia vivida" (Connelly y Clandinin, 1995, p. 16). No ahonda en la fijación de verdades, sino en la interpretación que el encuentro entre diferentes subjetividades generan de forma dialógica acerca de su trayectoria vital (Bligia y Bonet-Marti, 2009). Una experiencia, que según Contreras y Pérez de Lara (2010), nos remite a aquello que se vive, que deja efectos y huellas, aquello que nos pasa, nos afecta y nos transforma en el encuentro con otros y otras en escenarios particulares, como un horizonte de posibilidades.

El propósito de la investigación narrativa es comprender las trayectorias de vida y elementos que han intervenido en la elección de una vida académica exitosa y la influencia de la familia y los docentes en la misma a partir de las voces de las protagonistas. La muestra la forman cuatro mujeres gitanas que han transitado con éxito 
a través de diferentes itinerarios educativo: Carmen, Sofía, Natalia y Verónica (nombres ficticios). Dos de ellas han finalizado sus estudios universitarios y trabajan en la Fundación Secretariado Gitano (FSG); y otras dos se encuentran cursando estudios universitarios en la actualidad (Tabla 1). El criterio de selección fue que estuvieran realizando estudios universitarios y la mediación para conocerlas fue la Fundación Secretariado Gitano. Previo a realizar el trabajo de campo se elaboró y firmó un acuerdo de confidencialidad con cada una de ellas.

Tabla 1. Características de la muestra

\begin{tabular}{ccccc}
\cline { 2 - 5 } & Carmen & Sofía & Natalia & Verónica \\
\hline Edad & 39 & 39 & 21 & 20 \\
\hline $\begin{array}{c}\text { Estado } \\
\text { Civil }\end{array}$ & $\begin{array}{c}\text { Casada por rito } \\
\text { gitano }\end{array}$ & En pareja & Soltera con novio & $\begin{array}{c}\text { Casada por rito } \\
\text { gitano }\end{array}$ \\
\hline $\begin{array}{c}\text { Estudios } \\
\text { universitarios }\end{array}$ & Trabajo social & Sociología & $\begin{array}{c}\text { Recursos humanos y } \\
\text { relaciones laborales }\end{array}$ & Filología francesa \\
\hline
\end{tabular}

El procedimiento para la recogida de información han sido las entrevistas en profundidad, entendidas como conversaciones, como un espacio para abrirnos al intercambio dialógico que nos brinda la palabra (Sierra, 2013). Es por tanto el medio que nos permite construir paso a paso, minuciosamente y de manera compartida, la experiencia del otro.

Se han realizado -y grabado- un total de ocho entrevistas semiestructuradas (dos por persona, con una duración aproximada de una hora por entrevista), cuidando que estuvieran orientadas desde la escucha activa (Blanco y Sierra, 2015).

El guion contenía preguntas sobre diferentes dimensiones de análisis, ya que como se dijo anteriormente, este artículo parte de una investigación más amplia: vida familiar, social, escolar e individual. Una vez concluidas y transcritas las entrevistas, se entregaron a cada una de las participantes para su revisión y autorización del contenido de las mismas. Finalmente, se procedió a realizar el análisis de contenido, seleccionando y categorizando los párrafos relacionados con cada dimensión.

Las categorías de análisis seleccionadas para este trabajo han sido extraídas de la investigación original, referentes las dimensiones de análisis: familia, profesorado e historia escolar, tal como se recoge en la Tabla 2.

Tabla 2. Categorías de análisis

\begin{tabular}{cc}
\hline FAMILIA & DOCENTES \\
\hline Condiciones familiares & Tipo de relaciones \\
Referentes con estudios & Influencia (itinerarios) \\
Actitud hacia los estudios & Experiencias de relación \\
Relación en la vida escolar & Papel del profesorado \\
Roles de género & Ayuda en momentos de inflexión \\
\hline
\end{tabular}




\section{Resultados}

Los resultados aparecen organizados en torno a las dos dimensiones de análisis: la influencia de la familia y la del profesorado. Cada una de ellas se acompaña de fragmentos de las entrevistas, que evidencian como en situaciones distintas las mujeres gitanas están desarrollando proyectos de vida en los que el sentido de los estudios -base para una trayectoria de éxito- cobra relevancia apoyándose en la familia y los docentes.

\section{El papel de la familia: responsabilidad y acompañamiento para dar significado a la formación académica}

\section{Condiciones familiares: nivel socioeconómico, educativo y disposición de la vivienda}

Sería un ejercicio de ingenuidad desmentir la importancia del status socioeconómico y condiciones de la vivienda familiar para propiciar espacios para el estudio, pero en esta investigación, todas las entrevistadas muestran como no es éste un factor decisivo, ya que -en diferentes situaciones- han sabido sostener la importancia de los estudios en sus proyectos de vida en condiciones pocos favorables.

"Mi familia se dedicaba al trabajo esporádico en el campo y cuando no había trabajo en el campo lo compaginaban con la venta ambulante; y éramos seis hermanos. Nadie tenía estudios. Lo que recuerdo de la infancia es mucho trajín en la casa porque éramos muchos niños, o tener que incorporarnos más tarde a la escuela porque en el comienzo del curso estábamos fuera con la vendimia.(...) Nosotras teníamos una casa baja y hasta que mi padre empezó a hacer obras... dormíamos todos entre el salón y en la habitación que había sillones-camas. Después, cuando ya nos ampliaron la casa, había planta de arriba, pero no había sitio de estudio y en el salón era imposible porque era un jaleo continuo." (Carmen)

"Mi familia desde mi bisabuela se ha dedicado a la ganadería. Mi casa era como las casas normales. Nosotras no teníamos un sitio concreto para estudiar, solíamos hacerlo en el salón mi hermana y yo, aunque mis padres no nos ayudaban porque no sabían." (Sofía)

"Tengo tres hermanos, todos ellos niños... Yo soy la mayor y mi madre es la que se encarga de todos nosotros con la ayuda de mis abuelos, porque mi padre nunca ha estado con nosotros. Mi madre ha hecho de todo; actualmente está trabajando de camarera de piso, de limpiadora en un hotel... porque... no tiene terminada ni primaria. En mi casa el lugar de estudio era mi cuarto con mis hermanos. Ahí es donde me ponía a estudiar y así tenía que apañarme." (Natalia).

"Somos tres hermanos, yo soy la mayor. Mis padres se han dedicado siempre al mercadillo... Yo nunca he tenido un escritorio. Hacia los deberes en la mesa del salón o en el sofá o... (...) Mi madre nunca ha ido en su vida al colegio, por eso es analfabeta. Nadie en mi familia, por parte de madre, ha ido al instituto. Mi padre creo que se graduó... e hizo sus cursillos de vigilante de seguridad." (Verónica)

\section{Referentes con estudios superiores}

En este caso, dos de las entrevistadas señalan contar con referentes familiares con estudios superiores y ausencia de éstos en los otros dos casos. Para la continuidad educativa, más que la importancia de contar o no con dichos referentes, se destaca el peso que adquiere en los casos en los que sí aparecen, siendo un elemento influyente 
y favorecedor para el éxito y la vida académica prolongada. Así mismo, en todos los casos se aprecia la influencia que estas mujeres están teniendo en el seno familiar y en su comunidad al convertirse ellas mismas en referentes.

"A mi hermana la chica nosotros siempre la animamos y la poníamos a estudiar en el salón. Teníamos claro que tenía que terminar la secundaria." (Carmen)

"Yo he sido la primera con estudios superiores en mi familia. Mi madre, cuando hay que rellenar algún papel, siempre me lo da porque no lo entiende y ya se está dando cuenta de la importancia que tienen los estudios." (Verónica)

"En mi familia, la primera persona que hizo bachiller y fue a la universidad, fue mi hermana. Yo veía a mi hermana que se dedicaba a estudiar, y yo también quería. Fíjate, ahora sí, ya mis primos, los que van después, todos han estudiado, tienen su carrera. Tengo un primo hermano que su niña está estudiando un grado medio de gestión administrativa o algo similar. Él está súper emocionado de ver que su niña ha terminado bachiller y dice que es como nosotras de lista, que sirve para estudiar." (Sofía)

"Tengo una prima cinco años mayor que yo que ha ido a la universidad, pero su madre no es gitana. Ella ha sido la que me ha insistido más para que estudie. Ahora mis hermanos al verme a mí también están estudiando: uno está haciendo bachillerato y el pequeño está en la ESO. (...) Yo soy la típica que toda la familia cuando tienen algo que no saben, acuden a mí para que les intente ayudar, viendo la importancia de tener estudios.Además les están inculcando un montón a sus niños que tienen que estudiar y siempre me ponen de ejemplo. En el barrio y en el entorno también estoy viendo ya gente que me pregunta sobre los estudios de sus hijos." (Natalia)

\section{Significado de los estudios obligatorios y postobligatorios}

El significado que otorgan las familias a estudios obligatorios y postobligatorios no se ha producido de la misma forma, intensidad y momento en las diferentes historias. Los resultados muestran como en todos los casos -salvo en uno- las familias consideraban importante contar con estudios obligatorios.

"En mi casa se considera que por lo menos el graduado teníamos que tenerlo. Al principio no entendían por qué quería estudiar, porque nosotros con la venta nos iba bien, además yo era necesaria en el mercado. Mi padre estaba a la defensiva porque yo había renunciado a cosas que él hacía. Mi madre al principio tampoco entendía por qué quería estudiar, pero empezó a apoyarme en bachiller. Cuando en mi casa veían que avanzaba, que iba a la universidad, que seguía estudiando, no se lo creían. Fue tras la asistencia al acto de graduación cuando mi padre vio la importancia que tenía y empezó a valorar más todo el trabajo que yo había hecho durante la carrera." (Carmen)

"Mi padre siempre ha querido que yo estudie, pero mi madre, ahora que estoy en la universidad, es cuando se ha dado cuenta de la importancia que tiene este nivel de estudios. Cuando habla con la gente dice que se siente orgullosa de mí porque siguiendo las costumbres gitanas me he casado y estoy en la universidad." (Verónica)

Se destaca en ambas historias el cambio de consideración sobre la importancia de los estudios universitarios una vez finalizados, o valorando el esfuerzo vivido a través de los ojos de sus hijas. 
En los otros dos casos, además del apoyo familiar -sobre todo de las mujerespara la continuidad de la vida académica de las entrevistadas, subrayaría la aparición de palabras claves como "independencia", "orgullo", "superación", lo cual deja entrever como ellas apuestan por la transformación del rol de mujer gitana, posibilitando que sus hijas cuenten con herramientas para tomar sus propias decisiones y luchar en una comunidad patriarcal.

"En mi familia, desde mi bisabuela, las mujeres han tenido mucha fuerza, con una vida muy complicada, de mucha responsabilidad y siendo ellas las que decidían. Yo creo que eso me lo han transmitido y eso te marca. Mi padre nunca se opuso, pero era en especial mi madre la que siempre decía que nosotras teníamos que ser independientes y eso nos lo daba unos estudios. Que nosotras no dependiéramos de un hombre y nos viésemos en su situación. Yo me siento súper orgullosa de que mi madre tuviera ese pensamiento." (Sofía)

"Mi madre siempre me ha aconsejado que estudie y que me supere a mí misma, que luche por lo que quiera. Ella va por todas partes y lo primero que dice es que tiene una niña en la universidad y está súper orgullosa. Mi madre es mi principal apoyo." (Natalia)

\section{Relación de las familias con los centros educativos}

Aunque en este aspecto la mayoría de las entrevistadas señalan la participación de la familia en relación con los y las docentes, el hecho a destacar es el cambio en el tipo de relaciones atendiendo a la época en la que se han producido. Y subrayar también que en tres de los casos hacen referencia a la madre como la persona responsable de su educación y la encargada de acudir a las tutorías con sus maestros y maestras.

En el caso de las dos mujeres con mayor edad, una de ellas indica la inexistencia en cuanto a relaciones con sus docentes, la otra, aunque hace alusión al interés de su madre, muestra que las relaciones han sido menos intensas.

"Cuando yo era pequeña, en el cole llamaban a los padres para hablar. Mi madre jamás iba por si la hacían firmar y no sabía, o la ponían a leer o algo, ella sentía muchísima vergüenza. Ella siempre pensó que a sus hijas no les iba a pasar lo mismo." (Sofía)

"Recuerdo que teníamos que incorporarnos más tarde a la escuela porque estábamos fuera con la vendimia. Pero para el proceso educativo mi madre nos apuntó en su momento. Mi madre para esas cosas sí era muy organizada y no nos dejaba faltar al colegio. Si faltábamos llevaba su justificante, pero no solía ir a reuniones porque tenía que trabajar." (Carmen)

Sin embargo, las dos mujeres más jóvenes, cuando hablan sobre la relación de su familia y docentes, éstas son más continuas, con mayor implicación e interés. Esto se interpreta como un cambio en la conceptualización que las familias están generando respecto a los centros educativos, valorando la educación de sus hijas así como la importancia del intercambio con el profesorado.

"Cuando los maestros Ilamaban para alguna tutoría u otra cosa, mi madre era la primera, porque veía que yo tenía mucho interés, que siempre los profesores le decían que 
yo era muy inteligente, que podía llegar a todo lo que quisiera; eso a ella le llamaba mucho la atención y el miedo de que yo siguiese sus pasos y me pasara igual que a ella... siempre ha estado ahí al pie del cañón." (Natalia)

"Mi padre iba siempre que lo llamaban los profesores, sobre todo en $1^{\circ}$ ESO porque faltaba mucho. Mi padre iba... pufff... lo que pasa que... no ha sabido mucho... Él lo intentaba pero no sabía, se le iba de las manos. Yo era una adolescente..." (Verónica)

En este último fragmento aparece la figura paterna, algo que se puede relacionar con el hecho de que su madre, al no tener ningún tipo de estudios, no haya sentido la importancia de su implicación y compromiso en cuanto a relación con los centros educativos.

\section{Conservar tradiciones gitanas: concepción del matrimonio}

La entrada en la edad adulta es un momento clave en la vida de las mujeres gitanas, ya que siguiendo una de sus principales tradiciones, Ilega el momento de la boda y el "rito del pañuelo" y al mismo tiempo, la ruptura con la vida como estudiante. Los casos de nuestras entrevistadas explican dos situaciones diferentes: dos de ellas se han casado a través del rito gitano, y otras dos han decidido vivir una vida en pareja sin seguir la tradición. A pesar que en los cuatro casos se dan situaciones diferentes es de tener en cuenta que todas parten de un elemento común: el deseo de ser mujeres universitarias.

Por un lado, en las historias en las que han decidido romper con la tradición del matrimonio gitano, ambas mujeres afirman no haber sentido presión por parte de la familia, lo cual se interpreta como una ruptura con la herencia de tradiciones.

"Otros gitanos me ha cuestionado mucho porque mi pareja no es gitana, ni he vivido como las gitanas, pero mi familia siempre me ha respetado. Mis padres entendían y aceptaban que yo quisiera continuar mis estudios y postergar el tema de la pareja. Cuando era pequeña mi madre decía que quería que me casara con un gitano por el simple hecho de que nadie me rechazara. Cuando presenté a mi pareja mis padres lo único que dijeron es que querían que yo fuese feliz." (Sofía)

"Mi familia es gitana, pero ellos no han llevado las costumbres tan radicales, solo el sentimiento de la unidad familiar. En mi casa costumbres como bodas, pedimientos... esas cosas nunca se han visto, ni en mis tíos. Nunca han estado de acuerdo, sobre todo mi abuelo. Por eso mi madre nunca me ha inculcado valores que sigan esas tradiciones, al contrario, ella me ha animado siempre a seguir estudiando. Yo con mi novio llevo una vida normal, no me he casado y otros gitanos me critican, dicen que estoy 'apayá' y que yo no puedo seguir así y por eso me han discriminado, por no casarme y sacarme el pañuelo. A mí y a mi madre nos han cuestionado mucho por eso, pero mi madre no me dice nada para no preocuparme." (Natalia)

En otro de los casos, la protagonista ha contraído matrimonio por el rito gitano, y aunque afirma no haber sentido presión familiar en su decisión, el no haberse casado a una edad temprana ha contribuido a que pudiese finalizar sus estudios universitarios.

"A mí la gente me decía que me casara ya, pero en mi casa no, porque a mi madre yo se lo contaba todo. Ella sabía que hasta que yo no estuviese centrada y terminase mi carrera no me iba a casar. Mi familia nunca me cuestionó, a lo mejor porque decidí hacerlo de manera tradicional. Yo me casé con 32 años y me saqué el pañuelo con valor y sentido 
porque lo tenía muy claro. Y muchas veces pienso también que mi vida, con estudios y no casada hubiese sido muy distinta, porque ya no sé la proyección que hubiese tenido para viajar, hacer y deshacer. Lo que pasa es que en ese momento en el que yo ya estaba en expansión, conocí a mi marido y entonces eso limita un poco las metas." (Carmen)

Por último, en la otra historia en la que también optó por el matrimonio gitano, la entrevistada sufrió tensión familiar al anteponer los estudios al casamiento, aunque lo más significativo es ver cómo medió para conseguir compaginar tradición con vida académica.

"Yo siempre he tenido que luchar con mi gente. Tuve que hablar con mi madre porque me querían casar a los tres años de pedido, con 17 años, que también es mucho para los gitanos, y explicarle que me dejara que terminase por lo menos bachillerato e hiciese selectividad, porque a mí me asustaba el día de casarme y no seguir estudiando y ella fue muy comprensiva. Mi padre al contrario, estaba muy feliz que quisiera seguir estudiando. Al final me casé a los cinco años, lo cual es impensable, porque la gente iba a hablar de que ya no tenía el pañuelo. Con mis suegros también tuve que hablar, porque ellos no estaban acostumbrados a esperar tanto tiempo, aunque mi marido también estudia en la universidad. El día de la boda estaban todos orgullosos porque después de cinco años me saqué el pañuelo y sigo estudiando." (Verónica)

\section{El papel del profesorado en la acogida de alumnas gitanas}

La importancia de la figura docente en la construcción de los proyectos de vida de las estudiantes, tal y como muestran las siguientes evidencias, cobra fuerza en diferentes situaciones y diversas etapas educativas.

Un dato relevante es que en todas las historias recuerdan a sus maestros y maestras de educación infantil y primaria utilizando comentarios positivos. En todas se repiten palabras como ayuda, motivación, cariño, ánimo, comprensión, apoyo etc.

\section{Oportunidad para corregir errores (ESO)}

"Cuando iba a repetir en primero de ESO, le pedí a la Jefa de Estudios que no me pusieran en la clase de los repetidores, de los que no quieren estudiar. Ella tuvo que organizar otra vez todos los horarios para que yo me fuese a la clase de los niños que entraban nuevos y eso me ayudó mucho. Ya no había ese ambiente de clase donde no querían hacer nada." (Verónica)

\section{BUP: enseñarme a pensar}

"Recuerdo una profesora en BUP de filosofía, que siempre cuesta un poco, pero que ella lo hacía fácil. Ella nos enseñaba a pensar." (Sofía)

\section{Influencia en la elección de Bachillerato}

"Tuve a una profesora durante la ESO que me daba o ciencias naturales o matemáticas. Ella me decía que yo podía hacer el bachillerato que quisiera, porque tenía posibilida- 
des, y me aconsejó que hiciera el de ciencias porque todavía no tenía muy claro qué carrera coger, porque ese me daba más posibilidades. Hoy día se lo agradezco mucho." (Natalia)

\section{Etapa Universitaria}

"Cuando estaba estudiando Graduado Social, el profesor de antropología me ayudaba mucho. Me cuestionaba muchas cosas e incluso me invitaba a otras clases donde se hablaba de la comunidad gitana. Allí veía que él estaba más preparado que yo sobre los gitanos. Yo eso lo admiraba, es decir, cuestionaba cosas sobre los gitanos que yo no sabía argumentar y él sí." (Carmen)

\section{Apoyo material}

"Ellos nos han ayudado mucho, sobre todo en cosas materiales. Cuando han visto que me faltaba algo, siempre intentaban dármelo. Una vez en la ESO una maestra me regaló un libro de segunda mano porque yo no podía comprármelo." (Natalia)

\section{Discusión}

Los resultados expuestos confirman los hallazgos de otras investigaciones, en cuanto a la transformación de la mujer gitana y los elementos emergentes con los que compaginan tradición y progreso (Abajo y Carrasco, 2004; FSG, 2003, 2006, 2010; Valls y Aubert, 2003), la importancia que tiene el acompañamiento y aprobación por parte de las familias de la vidas académicas de sus hijas, y por último la influencia de la acogida y apoyo docente.

La familia representa un elemento clave en la vida de las entrevistadas, no sólo en relación a los estudios, sino en sus vidas de forma amplia. A diferencia de otras investigaciones donde se acentúa el nivel socioeconómico y educativo de las familias como un factor que puede contribuir negativamente (FSG, 2006; Gamella, 201), en las historias analizadas el sentido hacia los estudios ha sido más fuerte, independientemente del nivel educativo de los progenitores, las situaciones socioeconómicas o las condiciones de la vivienda. Se desprende, al igual que apunta FSG (2003), que las familias pueden contribuir al éxito educativo de sus hijas, facilitando el acceso a los estudios, los medios oportunos y evitando barreras, a pesar de que las situaciones sean adversas.

Al igual que en el estudio que realiza CREADE (2010), queda patente que la implicación de las familias en la escuela influye directamente en los resultados académicos y en la mejora de la convivencia con el centro educativo y por tanto en las oportunidades de éxito educativo de sus hijas.

Respecto a la influencia de referentes familiares con estudios superiores, los resultados no son concluyentes, ya que en los casos en los que se contaba con esa presencia ha resultado un factor influyente, mostrado en otras investigaciones (Abajo y Carrasco, 2004; Gamella, 2011). Pero no resulta decisivo, ya que en los otros dos casos donde no ha habido un referente familiar, eso no ha impedido que se den trayectorias de éxito educativo. 
En cuanto a la relevancia de las relaciones con los y las docentes, el hecho de tener relaciones positivas con el profesorado, de nombrarlos a lo largo de las narrativas, evidencia que es un factor que puede marcar la relación con los estudios no solo con nuestras protagonistas, sino que así lo entienden diferentes autores (Akey, 2006; Arguedas y Jiménez, 2007; Gamella, 2011). Liégeois (1988) concluye que la acogida y la afectividad de los profesores constituye una dimensión clave en el éxito educativo, realizando tareas de intermediación, reforzando su confianza, enfatizando la importancia de los estudios como instrumento de oportunidades. También Abajo y Carrasco (2004) hacen referencia a que el profesorado con altas expectativas sobre el alumnado propicia su éxito, haciendo igualmente referencia al hecho de que las muestras de afecto y confianza por parte del profesorado favorece su proceso de aprendizaje, un aprendizaje que en parte es relacional y que afecta a todos los niveles de la persona: intelectual, afectivo y social. Igualmente se reconoce en Hernández (2002) que las relaciones entre profesorado y alumnado inciden de un modo significativo en el rendimiento académico, destacando que las expectativas del profesorado influyen en el comportamiento del alumnado a través de la modificación de su autoconcepto y su éxito educativo.

Nuestros datos, por tanto, subrayan la importancia del apoyo de la familia y docentes para el éxito educativo, ampliando otras investigaciones (Gamella, 2011; Abajo y Carrasco, 2004). Y resulta crucial que familia y docentes remen juntos y aúnen esfuerzos. Pero no simplemente con afirmaciones, sino con prácticas y con acciones sostenidas (Gamella, 2011). Tal y como señalan Abajo y Carrasco (1994), es importante que el alumnado se sienta aceptado, querido y reconocido por lo que son y estimulados para lo que puedan Ilegar a ser.

Al igual que ocurre en la investigación que realiza CREADE (2010), estos datos nos llevan a la reflexión de la importancia del trabajo conjunto entre familia y profesorado, con el objetivo de que cada vez sean más las mujeres gitanas que puedan disfrutar de un futuro lleno de oportunidades a través de los estudios y la formación. "Cuando la familia apoya el sentido que tiene la escuela, existen más probabilidades de continuar estudiando" (CREADE, 2010: 78).

Finalmente, señalar que estas mujeres gitanas muestran como parecen tener más incorporado en sus proyectos vitales el valor de los estudios, mostrando pretensiones superiores a las de sus padres en cuanto al mundo académico y laboral. Demuestran un compromiso con la educación, asociado tal y como entiende Blanco (2015) al haber desarrollado un proyecto vital fuerte y sólido. En definitiva, mujeres gitanas que han enhebrado en familia e hilado en sociedad, proyectos de vida donde poner en relación tradición y progreso.

\section{REFERENCIAS BIBLIOGRÁFICAS}

Abajo, J. E. y Carrasco, S. (2004). Experiencias y trayectorias de éxito escolar de gitanas y gitanos en España. Madrid: CIDE/IM.

Akey, T. (2006). School context, student attitudes and behavior, and academic achievement. An exploratory analysis. MDRC (www.mdrc.org).

Andrés, M. T. (s.f.). La comunidad gitana y la educación. Publicación personal. Recuperado de: http://www2.uned.es/congreso-inter-educacion-intercultural/Grupo_ discusion_3/40.\%20T.pdf. 
Arguedas, I. y Jiménez, F. (2007). Factores que promueven la permanencia de estudiantes en la educación secundaria. Actualidades Investigativas en Educación, 7(3), 1-36. Recuperado de: http://revista.inie.ucr.ac.cr.

Blanco, N. (Coord.) (2015). Factores pedagógicos que favorecen el éxito escolar en estudiantes de enseñanza postobligatoria. Informe de investigación. Recuperado de: http://riuma.uma.es/xmlui/handle/10630/8035.

Blanco, N. y Sierra, N. (2015). Aprender a escuchar. Cultivar la disponibilidad en la investigación educativa. V Jornadas de Historias de Vida en Educación. Almería.

Bligia, M. y Bonet-Marti, J. (2009). La construcción de narrativas como método de investigación psicosocial. Prácticas de escritura compartida. Forum: Qualitative Social Research, 10(8). http://doi.org/10.17169/fqs-10.1.1225.

Bolivar, A. (2002). El estudio de caso como informe biográfico-narrativo. Arbor, 675, 559-578.

CNIIE (2014). La escolarización de la población gitana. Boletín de Educación, 3. Recuperado de: http://educalab.es/documents/10180/62610/Boletin3_Febrero2014. pdf/96a096d2-6b3d-4bab-805f-9465e9df6025.

Colectivo loé (2015). Las mujeres gitanas en la educación secundaria. Causas de abandono y éxito escolar. Madrid: CNIIE.

Connelly, M. y Clandinin, D. J. (1995). Relatos de experiencia e investigación educativa, en Larrosa, J. et al. (Comp.) Déjame que te cuente. Ensayos sobre narrativa y educación. (pp.11-59). Barcelona: Laertes.

Contreras, J. y Pérez de Lara, N. (2010). Investigar la experiencia educativa. Madrid: Morata.

CREADE (2010). Gitanos: de los mercadillos a la escuela y del instituto al futuro. Madrid: MEC.

Da Fosenca, A. (2009). La mujer gitana en el siglo XXI. Anales de Historia Contemporánea, 25, 234-238.

FSG (2006). Incorporación y trayectoria de niñas gitanas en la ESO. Madrid: CIDE/IM.

FSG (2010). Evaluación de la normalización educativa de las alumnas y los alumnos gitanos en la Educación Primaria. Madrid: CIDE/IM.

FSG (2013). El alumnado gitano en Secundaria. Un estudio comparado. Madrid: CNIIE.

García, S. y Blanco, N. (2015). Los ciclos formativos de grado medio: una opción para salir del laberinto personal y académico. Tendencias Pedagógicas, 25, 301-320.

Gamella, J. F. (2011). Historias de éxito. Modelos para reducir el abandono escolar de la adolescencia gitana. Madrid: MEC.

Hernández, F. y Padilla, P. (2013). Cuestionar el éxito y el fracaso escolar. Cuadernos de Pedagogía, 30, 56-59.

Hernández, E. (2002). Factores psicosociales en la adaptación y el desempeño escolar en una muestra gitana. Tesis Doctoral de la Universidad de Oviedo. Recuperado de: http://gip.uniovi.es/docume/gitanos/Tes_Gita_2002.pdf.

Laparra, M. (Coord.) (2011). Diagnóstico social de la comunidad gitana en España. Un análisis contrastado de la Encuesta del CIS a Hogares de Población Gitana 2007. Madrid: Ministerio de Sanidad, Política Social e Igualdad. 
Liégeois, J. P. (1998). Minoría y Escolaridad: el Paradigma Gitano. Madrid: Presencia Gitana/Interface.

Márquez, M. J. y Padua, D. (2009). La Institución educativa, un espacio a revisar: las adolescentes gitanas en su trayectoria educativa. Revista Interuniversitaria de Formación de Profesorado, 23(1), 73-88.

Montañés Álvarez, P. (2011). Una aproximación a la realidad de las mujeres gitanas desde la perspectiva de género. Acciones e Investigaciones Sociales, 29, 87-104.

Pujal, M. (2003). La tarea crítica: interconexiones entre el lenguaje, deseo y subjetividad. Política y Sociedad, 40(1), 129-140.

Puigvert, L. (2001). Las otras mujeres. Barcelona: El Roure.

Sierra, E. (2013). La secundaria vivida. Estudio narrativo sobre experiencias masculinas de fracaso escolar. Tesis doctoral. Universidad de Málaga. Recuperado de: http://riuma.uma.es/xmlui/handle/10630/6739.

Valls, R. y Aubert, A. (2003). Mujeres gitanas superando la exclusión social a través de la educación. Educación Social. Revista de Intervención Socioeducativa, 24, 23-34.

Villalba, P. (2000). La promoción de la mujer gitana desde una perspectiva de género. Gitanos. Pensamiento y Cultura, 5, 20-26. 